\title{
Impact of Rainwater Harvesting Structures on Groundwater Recharge Potential in India
}

\author{
Srikanta Mahato $^{1}$, A. K. Mishra ${ }^{1}$ and Subhankar Debnath ${ }^{2 *}$ \\ ${ }^{1}$ Indian Agricultural Research Institute, New Delhi, India \\ ${ }^{2}$ Centurion University of Technology and Management, Odisha, India \\ *Corresponding author
}

\section{A B S T R A C T}

Key w o r d s
Agricultural
production,
Rainwater
harvesting, Water
resources, Water
shortage

The available water resources are limited and/or seasonal, which made the water scientist to search for alternate solutions to the water shortage. Optimizing water usage and water conservation as a natural resource could help to solve water scarcity. One of the promising options to address this issue could be rainwater harvesting systems which conserve water resources and environment, reduce pollution, help to control flooding, and minimize negative of impact of weather change. In this present study, hydrologic impact of rain water harvesting structures (RWHS) was assessed in Arvari river catchment as alternate water resources for future possible utilization in agricultural purposes. The surface runoff volumes for potential recharge of four RWHS were estimated over catchment area. Results showed that minimum stored volume of $12000 \mathrm{~m}^{3}$ was experienced in Jhiri johad during the year 2011, whereas the Sankara bandh stored $50000 \mathrm{~m}^{3}$ of water during that year. The study revealed that structures could retain water up to 273 days, which suggests a great possibility to use harvested surface runoff to improve the catchment's agricultural output if the water can be used wisely.

\section{Introduction}

The rapid population growth along with industrialisation led to overuse of fresh water resources and consequently reduce groundwater levels. Rapid urbanization has led to less infiltration of rainfall and groundwater recharge potential has diminished (Ibrahim, 2009). Therefore, assessment of water resources potential (i.e. quantification of utilizable surface and ground water resources) is crucial for optimizing water allocation in different sectors including agriculture (Dash et al., 2020).

Past studies (Rodell et al., 2009; Shah et al., 2007) indicated that the exponential use of groundwater in recent decades has exacerbated serious problems with the depletion of aquifers, as groundwater tables are dropping rapidly in many states. Hence, feasible solution to sustain groundwater 
storage is utmost necessary, and rainwater harvesting (RWH) could be considered as a possible solution for sustainable groundwater management. It is the method of collecting and storing runoff in various types of structures during the heavy rainfall lin monsoon season. Keller et al., (2000) reported that RWH helps to produced higher crop production and yield by providing better accessibility of groundwater from rising water table.

However, systematic studies on impact of RWH structures and associated recharge on catchment-scale water balances are still lacking(Glendenning and Vervoort, 2010).Calder et al., (2006) found significant contribution on stream flow by RWH structures. The assessment of impact of RWH in catchment-scale is important for effective planning and management of water resources and it could highlight low dependability in drought years and smaller benefits to augment groundwater stores at higher degrees of catchment development (Kumar et al., 2008).

A key factor for perceiving RWH impact involves understanding rainfall-runoff variability and efficiency of RWH structures. However, it is not very well understood in India, particularly at the larger catchment scale. Keeping this in mind, an overarching goal and contribution of this study is to assess hydrologic impact of RWH structure for future utilization in agriculture.

\section{Materials and Methods}

\section{Study area}

This study focuses on Arvari river catchment in Rajasthan state of India. It is bounded by latitudes $27^{\circ} 01^{\prime} 30^{\prime \prime}-27^{\circ} 22^{\prime} 15^{\prime \prime} \mathrm{N}$ and longitudes $76^{\circ} 16^{\prime} 30^{\prime \prime}-76^{\circ} 04^{\prime} 55^{\prime \prime} \mathrm{E}$, has a drainage area of $476 \mathrm{~km}^{2}$ (Figure 1). The catchment area is located under semi-arid regions whereas Arvari river is an ephemeral river. Therefore, people of the catchment region are heavily dependent on RWH and ground water pumping. Total 366 rainwater harvesting structures (RWHS)are exist throughout the catchment.

Four RWHS, namely-Sankara, Beruji, Jhiriand Lalpura, were selected in this study for assessment of rainwater harvesting potential. The present study area was specifically chosen because hydrologic water balance is considered to be changed by large number of RWHS to the extent that the ephemeral river (i.e. Arvari river) has become almost perennial due to recharged aquifer. However, no clear evidence exists to support the fact.

\section{Data collection}

Digital elevation map (DEM) and reflection radiometer satellite data (ASTER)were obtained from global land cover facility (GLCF) to delineate the catchment area. ASTER-DEM data was used for preparing the drainage map, and deciding the location and type of RWHS. The LANDSAT imageries were downloaded from "GLOVIS: The USGS global visualization viewer". Survey of India (SOI) toposheets, groundwater data and rainfall data were obtained from the Map sales counter, Central ground water board and India Meteorological Department, respectively.

\section{Potential recharge from rainwater harvesting structures}

The potential recharge (i.e. surface runoff) from various structures was estimated in this study by using the water balance approach suggested by Sharda et al., (2006). Figure 2 shows locations of RWHS structures on Google Earth images and outlet of Arvari river catchment i.e. Sainthal Sagar dam. 
Considering negligible runoff into the structures, the potential recharge volume $\left(R_{\mathrm{ep}}\right.$, $\mathrm{m}^{3}$ ) on non-rainy days is estimated as:

$$
R_{e p}=A_{s}(\Delta h-E T)-O_{t}(1)
$$

Where,

$\mathrm{A}_{\mathrm{s}}=$ Average surface area $\left(\mathrm{m}^{2}\right)$,

$\mathrm{ET}=$ Potential evaporation $(\mathrm{m})$,

$\mathrm{O}_{\mathrm{t}}=$ Overflow $\left(\mathrm{m}^{3}\right)$, which did not occur during the field data collection; and

$\Delta \mathrm{h}=$ Increase in depth (m) in water level of the structure.

\section{Results and Discussion}

\section{Estimation of surface runoff volume for potential recharge $\left(\mathbf{R}_{\mathrm{ep}}\right)$}

The estimated surface runoff volume for potential recharge $\left(R_{e p}\right)$ during the period 2011-2012 from the four concerned RWHS is presented in Table 1 . The considerable variation in the $R_{e p}$ of the RWHS is consequenced because of varying contributing catchment size and the erratic rainfall experienced in the respective years. In the Jhiri johad, the minimum stored volume of $12,000 \mathrm{~m}^{3}$ was observed during the year 2011, and the corresponding estimate at the Sankara bandh was approximately $50,000 \mathrm{~m}^{3}$. However, Lalpura johad stored water for much longer duration (i.e. 240 days) as well as slightly higher volume as compared to Jhiri. The $20 \%$ increase in rainfall in the year 2012 with respect to rainfall in 2011resulted $10 \%$ surge in the existing storage, and the duration of water storage also improved from 201 days to 270 days. Moreover, the geological and edaphic conditions of the potential RWHS sites augmented the improvement in storage volume and duration to greater extent. The detailed quantification of storage volume and duration at the potential RWHS locations furnished a clear insight of the existing storage potential, viz., specially designed structures and which can be suitably modified further during extreme rainfall scenarios; thereby serves the horticulture plantation and agriculture production in a better way.

\section{Effect of rainwater harvesting on groundwater recharge}

To develop a better understanding of the groundwater table fluctuations resulting from construction of large number of RWHS in the catchment, the groundwater table fluctuation during the period 1982-2012 were analysed at two observation well locations of Rajgarh and Kishangarh, and presented in Figure 3. The observation well located at Rajgarh is at the closest proximity of constructed RWHS, depicting the increased RWH induced recharge as evidenced from the increased water table label from $16 \mathrm{~m}$ in 1985 to $8 \mathrm{~m}$ in the year 1995. It indicates the positive impact of RWHS on the aquifer recharge, and subsequent reduction in depth of groundwater table. From Fig. 3, it can be surmised that the groundwater table declined in the successive time scales and reached to a lower depth of 17 $\mathrm{m}$ in the year 2001. This could be attributed to the significant deficit in rainfall and increased ground water draft because ofextensive agricultural operation and domestic water demand. Moreover, the rainfall and water table fluctuation statistics at the Kishangarh revealed that there exists a different relation between rainfall and water table fluctuation under similar rainfall magnitude of Rajgarh due to very sparse number of RWHS located in that region. Further, the water table declines from $23 \mathrm{~m} 35 \mathrm{~m}$ during the period 1985-1995 which could be attribute to the increased population growth. This finding is supported by the perusal of water table fluctuation data from other stations, despite the low specific yield $(2.63 \%)$ and poor transmission characteristics. The temporal fluctuation of the water table in the seven 
concerned locations of the study area is illustrated in Figure 4. The fluctuation of the water table can be seen as having minor variations during the years of 1982 to 1990 due to sufficient rainfall during that period. It is evident from the Figure 3 that The water level in the Kishangarh was the deepest in relation to other observational sites.

\section{Spatial variability in water table fluctuation}

In terms of spatial variability maps of decadal changes, the long-term mean annual water table fluctuation of 29 observation wells for the period 1982-2012 is represented in figure 5 and compared with the RWHS in the study.

As envisaged from the figure, the groundwater table remained close to the surface, i.e., up to $7 \mathrm{mbgl}$ prior to the construction of RWHS in the upper reaches while in the remaining lower reaches located in south-west direction had attained a depth of $31 \mathrm{mbgl}$ during the decade 1982-1991.

Similarly, during the next decades the water table had enumerated a significant escalation in the upper and middle reaches which have undergone a considerable number of new RWHS; thereby resulting in water table fluctuation between 5.67 to $33.6 \mathrm{mbgl}$. Moreover, the upper and middle reaches have shown anupward rise in the water table and the lower reaches have illustrated continuous decline in the water table, wherein a water table difference of $2 \mathrm{~m}$ was seen over the two successive decades.

During 2002-2012, the rise in water table fluctuation gone up to the range of 7.03 to $53.72 \mathrm{mbgl}$ with similar spatiotemporal trend is exhibited across all the reaches of the study location.

The abrupt increase in the water table magnitude could be attributed to the presence of in-sufficient number of RWHS followed by enhanced draft requirement from the increasing population. The catchment has been categorized into 6 zones based on RWHS density which indicates absence of RWHS in the Zone 1 as evidenced from the lowest water table depth of $53.72 \mathrm{mbgl}$.

As per the variability in the catchment area, rainfall distribution, type of structure and their location, considerable alterations in the estimated recharge volumes of the four representative RWHS was observed.

As a proof of concept, $20 \%$ increase in the rainfall magnitude during the year 2012 improved the recharge volume by a magnitude of $30 \%$ than that of the year 2011 . Moreover, the capability of some structures to retain water for a period of up to 273 days behaved as an excellent alternative during the lean periods by improving the groundwater recharge.

Table.1 Estimated potential recharge $\left(\mathrm{R}_{\mathrm{ep}}\right)$ at RWHSlocations in the Arvari River catchment

\begin{tabular}{|l|l|c|c|c|c|}
\hline \multirow{2}{*}{$\begin{array}{c}\text { Structure } \\
\text { name }\end{array}$} & RWHS type & \multicolumn{2}{|c|}{$\mathbf{R}_{\text {ep }}$ (in '000 m ) } & \multicolumn{2}{c|}{$\begin{array}{c}\text { No. of Days of Water Storage in the } \\
\text { RWHS }\end{array}$} \\
\cline { 3 - 6 } & & $\mathbf{2 0 1 1}$ & $\mathbf{2 0 1 2}$ & $\mathbf{2 0 1 1}$ & $\mathbf{2 0 1 2}$ \\
\hline Sankara & Bandh & 47 & 55 & 169 & 260 \\
\hline Beruji & Bandh & 20 & 27 & 138 & 201 \\
\hline Jhiri & Johad & 12 & 19 & 273 & 270 \\
\hline Lalpura & Johad & 15 & 23 & 240 & 270 \\
\hline
\end{tabular}




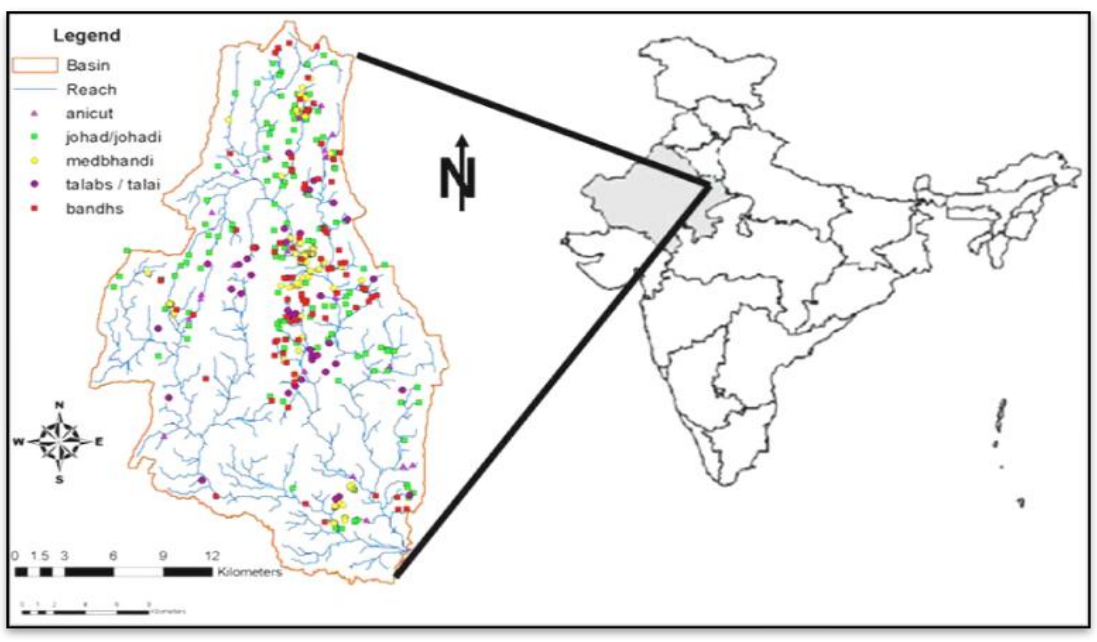

Figure.1 Arvari river catchment
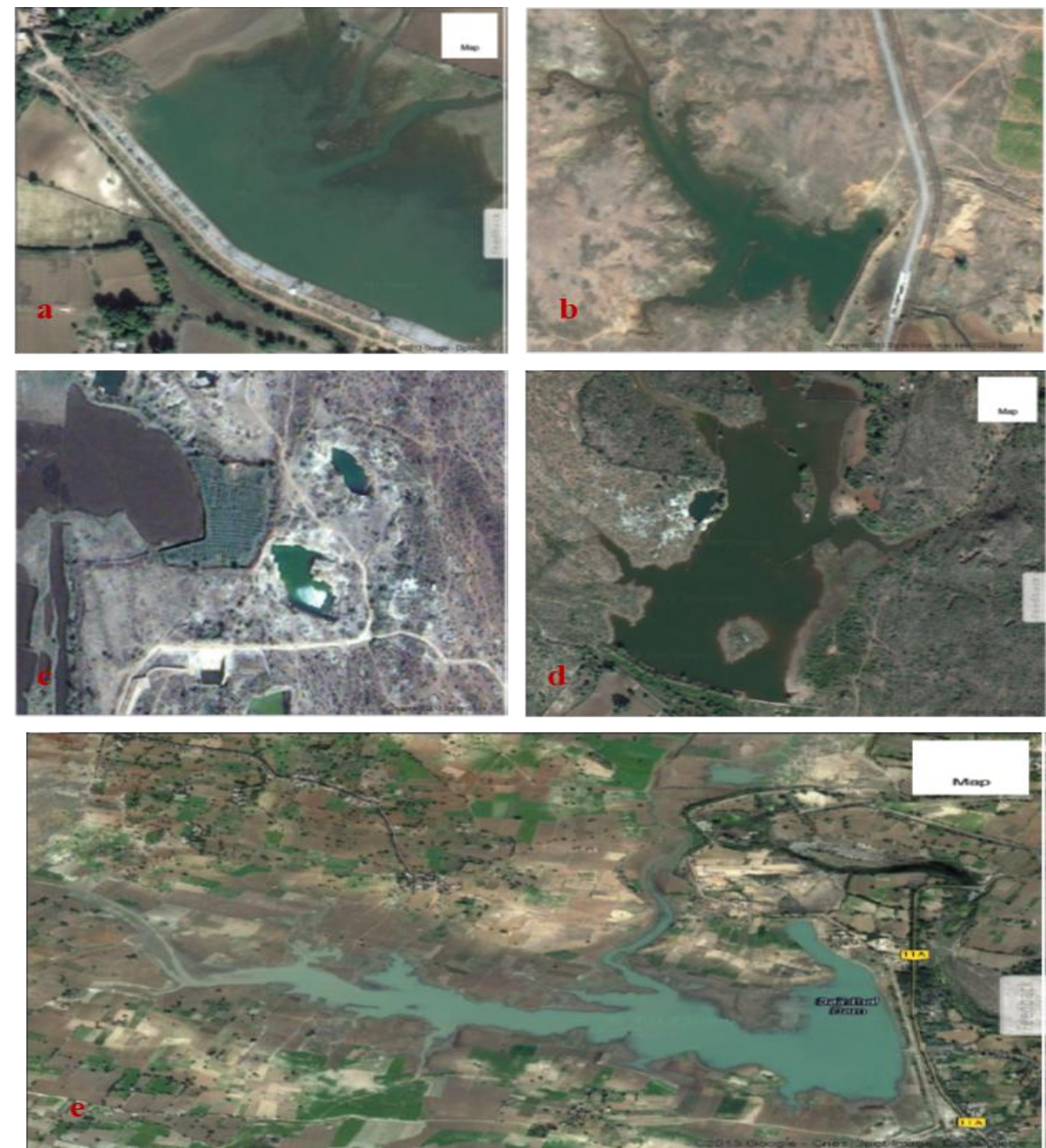

Figure.2 Google Earth images of various RWHS (a-d) and outlet of Arvari river catchment (e) 


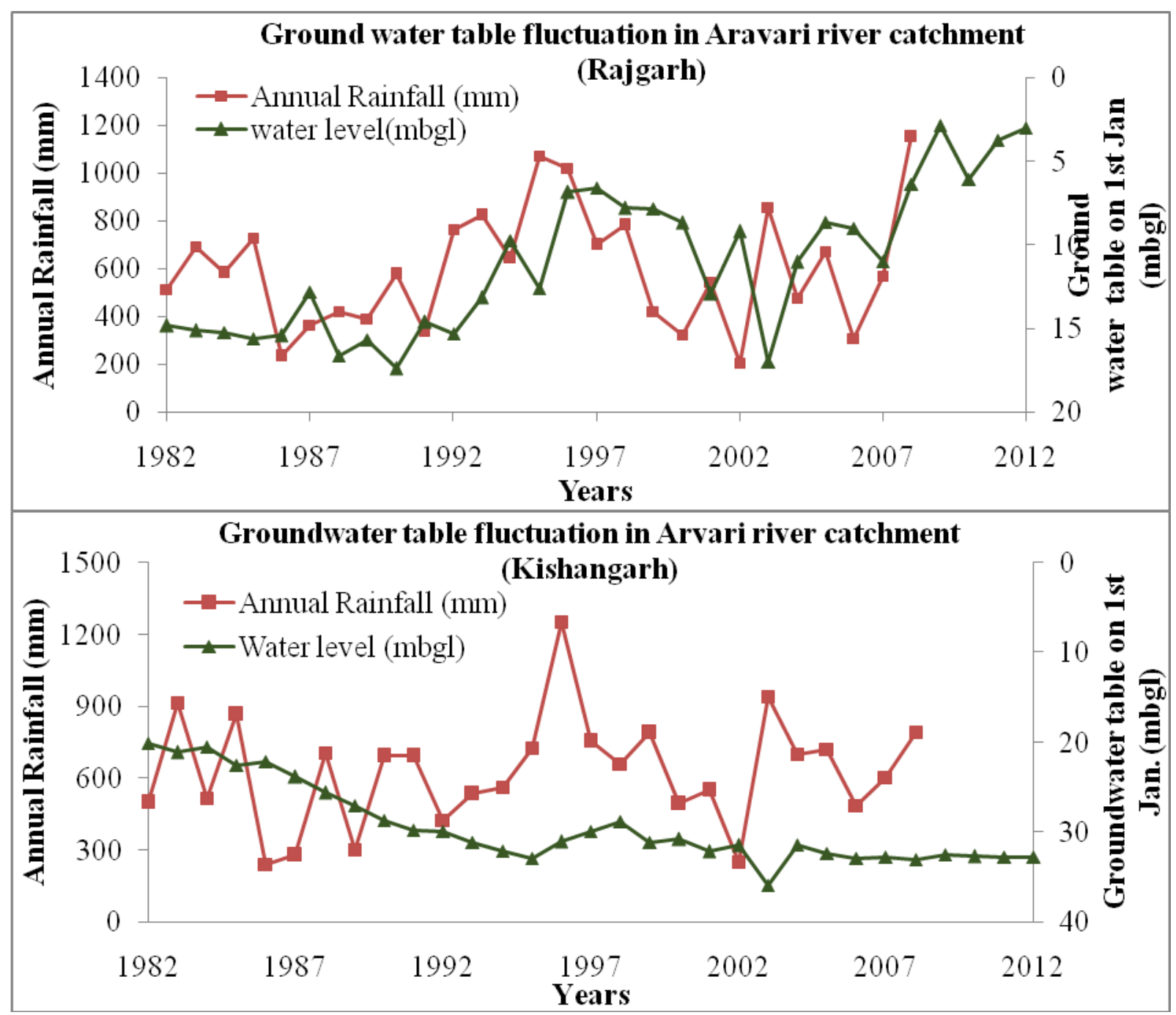

Figure.3 Long-term groundwater table fluctuation along with annual rainfall at two observation well locations- Rajgarh and Kishangarh in the catchment

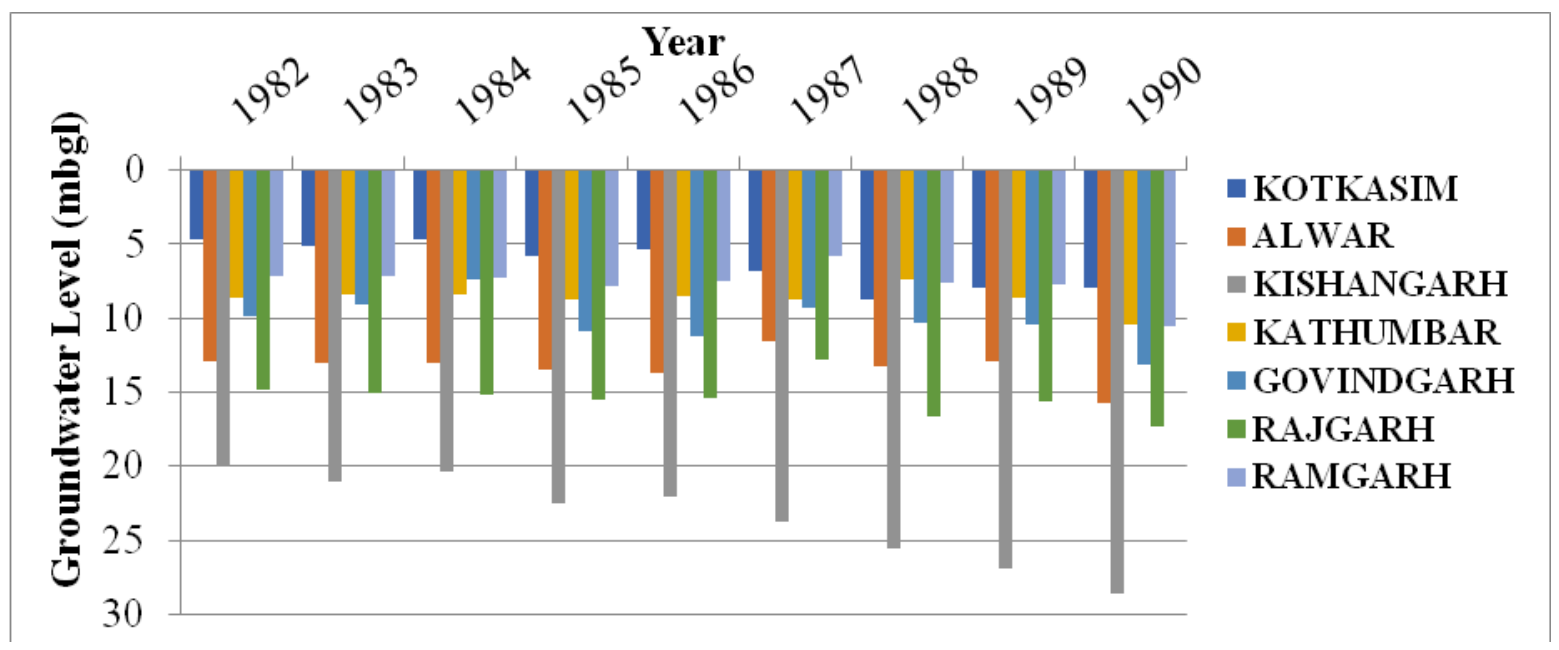

Figure.4 Water table fluctuation at different observation location in the study area 


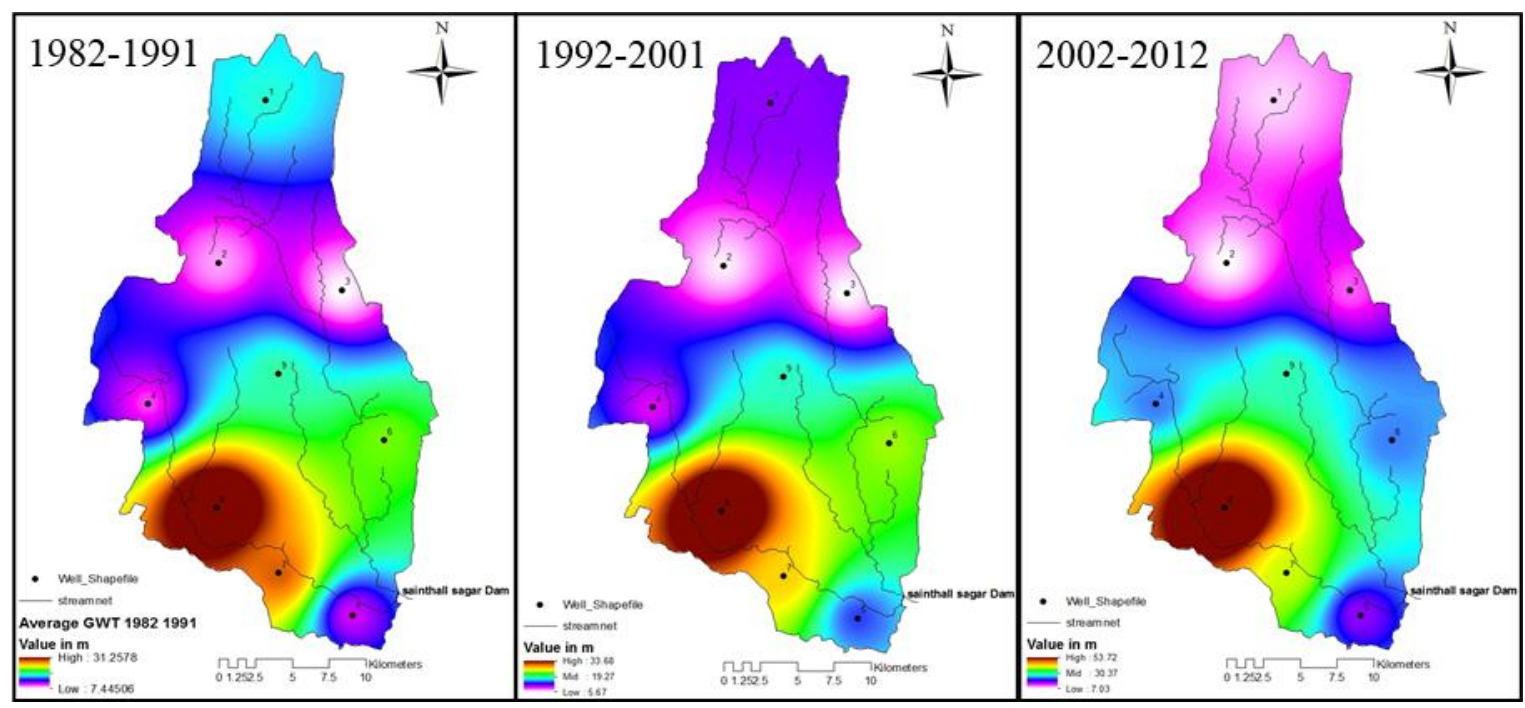

Figure.5 Spatial changes in mean water table depth between 1982-2012 in Arvari river catchment

The extent of groundwater recharge combinely affected by the storage volume, storage duration, and exclusively by the aquifer characteristics where the storage structure is located. Based on the spatiotemporal studies of the water table fluctuation, a positive impact on the water table fluctuation can be seen in the upper and middle reaches after the year 1985 which could be attributed to the large scale construction of RWHS, approximately 366 nos. Furthermore, a difference in the maximum and minimum water table magnitude during last three decades were $24.00,28.01 \mathrm{~m}$ and $46.69 \mathrm{~m}$, respectively, pointed at a rapidly deteriorating scenario that requiring immediate adaptive measures for its rehabilitation. Further, increased draft requirement from the agricultural and domestic sector need to be maintained to its optimum level in order to plan for a sustainable groundwater development strategy.

In this study, to estimate the potential recharge volume at respective RWHS, the approach suggested by Sharda et al., (2006) was adopted and found to be in line with the study outcomes of Badiger et al., (2002).
However, only $10 \%$ of rainfall is found to be transformed into potential recharge at the concerned RWHS.

Although farming is the major source of livelihood in the Arvari river catchment, the poor research and development infrastructure lead to limited field data availability, and subsequently results less trustworthy outcomes. Due to the location of RWHS in the remote areas, measurements of the stored water surface area in RWHS were quite intricate in nature.

With all these odd scenarios, the constructed RWHS has improved the life style of the people living in this locality by enhancing the groundwater recharge significantly during inadequate monsoon rainfall.

Conclusively, this applicability of this study can be evaluated under varying edaphic, agroclimatic and geo-hydrologic regions with wide range of rainfall variability scenario. The identified potential recharge estimates will be a guiding tool for local as well as regional scale ground water managers. Although rainwater harvesting is extensively implemented in India, there is a necessity for better understanding of its impacts catchment 
hydrology and underlying stakeholder. The present study was undertaken to assess the impact of RWHS on catchment-scale groundwater recharge in Arvari river catchment, India. The potential recharge volume available from the structures were estimated in this study revealed that larger recharge volumes ( $>30 \%$ as compared to 2011) were observed in 2012 due to nearly 20 $\%$ more rainfall in 2012.

Because of geological and edaphic conditions of selected RWHS locations, water could be stored in the structure for minimum duration of 201 days to a maximum of 270 days. It shows the possibility for storing rain water in specially adapted structures to be used for other productive purposes such as agricultural farming. The study reveals that presence of densely constructed RHWS could make a significant rise in the groundwater table.

Additionally, spatio-temporal analysis of the groundwater table fluctuation because of existing huge number of RWHS (366 nos.) revealed that substantial increase in water table has occurred after the year 1985 in upper and middle region of the catchment.

\section{References}

Badiger, S., \& Sakthivadivel, R. (2002). Preliminary assessment of a traditional approach to Rainwater Harvesting and Artificial Recharging of Groundwater in Alwar District, Rajasthan. Annual Partners' Meet 2002, IWMI-TATA Water Policy Research Program: 1-18.

Dash, S. S., Sena, D. R., Mandal, U., Kumar A., Kumar, G., Mishra, P.K., Rawat, M., 2020. A hydrological modellingbased approach for vulnerable area identification under changing climate scenarios. Journal of Water and Climate
Change,https://doi.org/10.2166/wcc.202 0.202 .

Glendenning, C. J., \& Vervoort, R. W. (2010). Hydrological impacts of rainwater harvesting (RWH) in a case study catchment: The Arvari River, Rajasthan, India. Part 1: Field-scale impacts. Agricultural Water Management, 98(2), 331-342.

Keller, A. A., Sakthivadivel, R., \& Seckler, D. W. (2000). Water scarcity and the role of storage in development (Vol. 39). IWMI.

Kumar, M. D., Patel, A., Ravindranath, R., \& Singh, O. P. (2008). Chasing a mirage: water harvesting and artificial recharge in naturally water-scarce regions. Economic and Political weekly, 61-71.

Ibrahim, M. B. (2009). Rainwater harvesting for urban areas: a success story from Gadarif City in Central Sudan. Water resources management, 23(13), 27272736.

Muralidharan, D. and Andrade, R. (2007). "Evaluation of check-dam recharge through water-table response in ponding area." Current Science 92: 1349-1351.

Rodell, M., Velicogna, I., \& Famiglietti, J. S. (2009). Satellite-based estimates of groundwater depletion in India. Nature, 460(7258), 999-1002.

Shah, T. (2007). The groundwater economy of South Asia: an assessment of size, significance and socio-ecological impacts. The agricultural groundwater revolution: Opportunities and threats to development, 7-36

Sharda, V. N., Kurothe, R. S., Sena, D. R., Pande, V. C. and Tiwari, S. P. (2006). Estimation of groundwater recharge from water storage structures in a semiarid climate of India. Journal of Hydrology, 329(1), 224-243. 


\section{How to cite this article:}

Srikanta Mahato, A. K. Mishra and Subhankar Debnath. 2020. Impact of Rainwater Harvesting Structures on Groundwater Recharge Potential in India. Int.J.Curr.Microbiol.App.Sci. 9(06): 66-74. doi: https://doi.org/10.20546/ijcmas.2020.906.008 